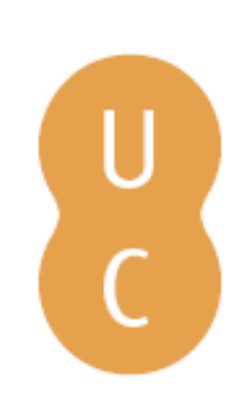

\title{
nombalina
}

\section{Monarcas persas nas Histórias de Heródoto: lei e liberdade, fundamentos da ideologia monárquica}

\author{
Autor(es): $\quad$ Soares, Carmen \\ Publicado por: Imprensa da Universidade de Coimbra \\ URL \\ persistente: URI:http://hdl.handle.net/10316.2/45221 \\ DOI: $\quad$ DOI:https://doi.org/10.14195/978-989-26-1626-1_12 \\ Accessed : $\quad$ 26-Apr-2023 16:14:07
}

A navegação consulta e descarregamento dos títulos inseridos nas Bibliotecas Digitais UC Digitalis, UC Pombalina e UC Impactum, pressupõem a aceitação plena e sem reservas dos Termos e Condições de Uso destas Bibliotecas Digitais, disponíveis em https://digitalis.uc.pt/pt-pt/termos.

Conforme exposto nos referidos Termos e Condições de Uso, o descarregamento de títulos de acesso restrito requer uma licença válida de autorização devendo o utilizador aceder ao(s) documento(s) a partir de um endereço de IP da instituição detentora da supramencionada licença.

Ao utilizador é apenas permitido o descarregamento para uso pessoal, pelo que o emprego do(s) título(s) descarregado(s) para outro fim, designadamente comercial, carece de autorização do respetivo autor ou editor da obra.

Na medida em que todas as obras da UC Digitalis se encontram protegidas pelo Código do Direito de Autor e Direitos Conexos e demais legislação aplicável, toda a cópia, parcial ou total, deste documento, nos casos em que é legalmente admitida, deverá conter ou fazer-se acompanhar por este aviso.

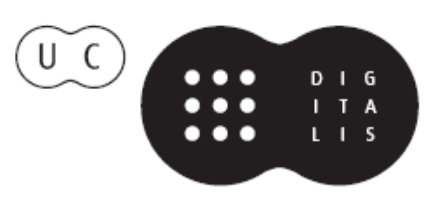




\section{Arqueologias de Império}

\section{Delfim Leão, José Augusto Ramos, Nuno Simões Rodrigues (coords.)}

IMPRENSA DA UNIVERSIDADE DE COIMBRA 


\title{
Monarcas persas nas Histórias de Heródoto: LEI E LIBERDADE, FUNDAMENTOS DA IDEOLOGIA MONÁRQUICA ${ }^{1}$ (Persian Kings in Herodotus' Histories: Law and Freedom, roots of the monarchic ideology)
}

\author{
CARMEN SOARES
}

(cilsoares@gmail.com; ORCID: 0000-0003-3005-4635)

Universidade de Coimbra, Centro de Estudos Clássicos e Humanísticos

\begin{abstract}
Resumo - O presente estudo, apoiando-se na teorização política que o próprio autor apresenta em 3.80-82, passa em revista passos fundamentais das Histórias para a caracterização dos governos monocráticos dos soberanos persas. O que se busca clarificar é a forma como a relação desses governantes com a lei e a liberdade/servidão em que se encontram os que governam nos levam à conclusão da inexistência de uma figura modelar do monarca. Heródoto oferece, sim, dos monarcas tanto «retratos mistos» (daqueles que se governam ora com justiça, ora de modo despótico, como Ciro e Dario e, antes deles, Déjoces da Média), como um «retrato puro» (do tirano insolente, Cambises).
\end{abstract}

Palavras-chave: teorização política; monarquia; tirania; lei; liberdade.

AвstraCt - In this paper, after a brief analysis of Histories 3.80-82, the author addresses the issue of the Persian monarchs' autocratic governments. What he tries to make clear is the close relationship there is between those sovereigns and the law, and also the degree of freedom or slavery experienced by the people under their rule. The main conclusions reached are: none of Herodotus' Persian kings corresponds to a portrait of the perfect monarch; on the contrary, we can find what could be called «mixed portraits» (when a king acts in some cases justly, but in others assumes a despotic way of ruling - as do Cyrus and Darius, as also Dejoces from Media) and a "pure portrait» (of the insolent tyrant, Cambyses).

KEYwORDs: political theory; monarchy; tyranny; law; freedom.

Fonte escrita incontornável para o conhecimento da visão grega do séc. $\mathrm{V}$ a. C. sobre a ideologia das monarquias orientais, as Histórias de Heródoto desde sempre cativaram o leitor, graças sobretudo à sua forma atraente de apresentar os factos. Vestidos com uma roupagem bastante próxima das personagens trágicas do drama ateniense, os protagonistas da história persa são, não obstante esse "colorido dramático», alvo de um tratamento políticofilosófico coerente e devidamente fundamentado. O retrato dos monarcas persas só pode ser bem compreendido, se tivermos em conta a articulação entre dois

\footnotetext{
${ }^{1}$ Trabalho desenvolvido no âmbito do projeto UID/ELT/00196/2013, financiado pela FCT - Fundação para a Ciência e a Tecnologia.
} 
vetores de análise que emanam da duplicidade genética do discurso político: por um lado patenteando uma reflexão teórica sobre o assunto (theoria), pelo

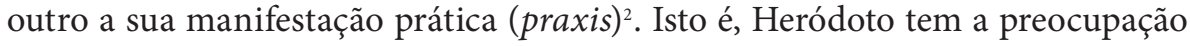
racional de fornecer uma reflexão epistemológica sobre o regime monárquico (entendido no sentido neutro e etimológico de 'governo de um só'), a qual serve, como já tive oportunidade de defender noutro lugar ${ }^{3}$, de «ficha de leitura» para os perfis concretos que vai apresentando do monarca (termo também usado com o seu valor básico de 'governante único'). Consciente desta dupla perspetivação do universo político do texto herodotiano, entendi dividir em duas partes complementares o meu estudo, a saber: 1. Fundamentação teórica do regime monárquico; 2. Materializações do regime: os retratos dos monarcas.

\section{FUndamentaÇÃo teórica do Regime MONÁRQUiCo}

É no livro III (caps. 80-82) que deparamos com a apresentação de seis formas de governação distintas, passíveis de distribuir por dois grupos opostos do ponto de vista moral, a que entendo chamar, com base na caracterização ética de que são alvo, de «os melhores» e «os piores» regimes ${ }^{4}$. Sem nunca deixar transparecer a sua opinião sobre a presente matéria, Heródoto coloca na boca de três nobres persas a apresentação dos fatores que contemporaneamente seriam tidos, pelo menos entre algumas elites pensantes gregas, como «marcadores da identidade» de cada uma das politeiai. Se é verdade que, mesmo sem lhes atribuir nomes diferentes, o historiador dá conta de uma forma "perfeita» (ou, como se lê em grego, aristos) e de outra «degenerada» (correspondente a kakistos) para a democracia e a oligarquia, já quando está em causa o 'governo de um só' são dois os nomes empregues. Mounarchie (correspondente iónico do substantivo ático monarchia, que havia de entrar, via latim, nas línguas modernas), pelo sentido neutro que comporta, vem aplicada tanto ao modelo

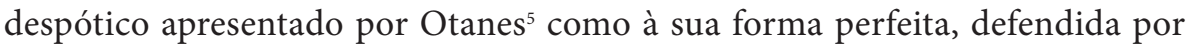
Dario $^{6}$. O outro dos nomes usado para apelidar a constituição monocrática é tyrannis $^{7}$ e restringe-se, tal como hoje, ao perfil opressivo do que continuamos a designar de 'tirania'.

${ }^{2}$ Já procedi anteriormente a uma análise mais alargada da abordagem theoria e praxis política nas Histórias de Heródoto - Soares 2014a - bem como à comparação entre os retratos dos regimes tirânico e democrático - Soares 2014b.

${ }^{3}$ Cf. Soares 2016.

${ }^{4}$ Cartledge $(2009,21)$ também reconhece neste trecho das Histórias a identificação de seis formas de constituição, gérmen da tipologia platónica, constituída por três forma «boas»e outras tantas «degeneradas» de constituição. O paralelismo entre Heródoto e as seis constituições reais caraterizadas no diálogo $O$ Político de Platão já foi objeto da minha reflexão (Soares 2014a).

${ }^{5} 3.80 .3$.

${ }^{6} 3.82 .3,4$.

${ }^{7} 3.81$.1. 
Embora a questão da historicidade do «Diálogo dos Persas» permaneça em aberto e, quanto a mim, seja marginal relativamente àquele que me parece o motivo principal para a sua inclusão na obra (a racionalidade do Autor), o facto é que Heródoto introduziu o episódio com a afirmação expressa de que foram proferidos discursos inacreditáveis (na opinião de alguns Gregos), mas a verdade é que foram proferidos ${ }^{8}$. Esta espécie de juramento de autenticidade não tem para mim que ser entendida como uma prova irrefutável de que o historiador acreditava que os Persas tivessem mesmo tido semelhante conversa, algures entre 522/21 a. C., por ocasião do golpe que levou à deposição do mago Gaumata. $\mathrm{O}$ seu desígnio poderia apenas ser dar a entender ao público que, tal como alguns Gregos repudiavam a tirania, avaliada pelo Coríntio Socles como a mais injusta e sanguinária das realizações humanas ${ }^{9}$, também os Persas (pela boca de Otanes) concebiam o regime com idênticas cores negras. Em suma, Gregos e Persas aparecem irmanados no seu ódio à tirania, perspetiva concordante com a funcionalidade aqui dada pelo historiador ao Bárbaro: paradigma do Grego.

Atentemos agora, ainda que sumariamente, nos elementos caracterizadores e distintivos das duas formas de governo de um só. Na base da argumentação sobre as várias constituições deparamos com um princípio que haveria de permanecer como fundamento da filosofia política posterior, a saber: a correlação entre ética e política. Este diálogo pode, no entanto, dar-se em sentidos opostos. Esclarecendo melhor: ou é o exercício do poder absoluto que influencia o carácter do governante ou, ao invés, cabe a este aspeto determinar a forma de governação. A conceção de tirania (retratada por Otanes e Megabizo) deriva da primeira leitura, donde ressalta a ideia de que, mesmo ao indivíduo com uma conduta moral exemplar (a quem os Gregos da época atribuíam o título de 'o melhor dos homens ${ }^{110}$ ), o poder ilimitado corrompe- $\mathrm{O}^{11}$. Já a monarquia (tal como a apresenta Dario) fica a dever ao ethos do governante o estatuto de regime perfeito (aristos) e regenerador, i. e., o único que pode restabelecer a ordem social arruinada sob as disputas dos oligarcas pelo protagonismo ${ }^{12}$ ou sob as cumplicidades danosas dos governantes de origem popular ${ }^{13}$. Em suma, o carácter do governante afigura-se um motivo central da aceção clássica grega da ideologia política.

${ }^{8}$ 3.80.1. Todas as traduções apresentadas são da minha autoria.

${ }^{9} 5.92 \alpha 1$.

${ }^{10} 3.80 .3$.

${ }^{11}$ Note-se que, como alerta a helenista Emily Baragwanath $(2015,21-22)$, a apreciação de Otanes não deve ser entendida como evidência de que Heródoto acreditava na universalidade de comportamentos humanos, o que implicaria que, nas Histórias, todos os governantes autocráticos teriam percursos absolutamente idênticos. Segundo propõe a autora, a presente observação do aristocrata persa não deve, pois, ser lida como uma verdade absoluta, aplicando-se, concretamente, ao comportamento de Cambises.

123.82 .3 .

13 3.82.4. 
Das considerações acabadas de fazer retiramos também a conclusão de que a tirania corresponde à versão defeituosa do governo de um só, como bem confirma o facto de nas Histórias vir sempre associada a conotações pejorativas ${ }^{14}$. $\mathrm{Na}$ verdade, o regime colhe apenas críticas, todas elas verdadeiros atentados contra os principais fundamentos da vida em sociedade, tal como os Gregos a concebiam: as normas (sejam elas sociais ou jurídicas, noções ambas contidas no termo nomos), a moderação (reverso da condenada hybris) e a justiça (ou cumprimento das leis). Em concreto, esses vícios do poder tirânico deduzimo-los, respetivamente, das seguintes práticas, denunciadas por Otanes: alterar os costumes pátrios, exercer violência sobre as mulheres e condenar à morte sem julgamento ${ }^{15}$.

Para que fique completo o retrato da tirania, falta ainda lembrar dois traços de carácter do tirano: a inveja (incompreensível numa pessoa que vive na prosperidade) e a insegurança (que se traduz na desconfiança que domina as relações do governante com os súbditos e na sua recetividade face às calúnias). Porque a personagem que procede a esta caracterização do regime é o defensor da democracia, faz sentido que, tendo em mente dois mecanismos identitários da sua constituição preferida, aponte à tirania a seguinte falha: a ausência de controlo das finanças públicas e da atuação do governante. Ou seja, como diz Otanes, o tirano não tem que prestar contas e faz o que lhe apetece ${ }^{16}$.

Por contraste com esta caracterização detalhada da ideologia tirânica, o perfil da monarquia assenta apenas na já referida ética do governante e num valor que, modernamente, associamos mais à democracia: a liberdade. No termo da fala de Dario deparamos com as seguintes declarações:

Para resumir tudo o que foi aduzido num único termo: a liberdade donde nos veio e quem nos a deu? Do povo, da oligarquia ou de um monarca? Sou, por conseguinte, da opinião de que, visto nós termos sido libertados por um único homem, defendamos esse tipo de regime e, além disso, porque temos por bem não dissolver os costumes pátrios! Realmente esta não é a melhor atitude. ${ }^{17}$

Duas ideias sobressaem da argumentação final do nobre persa para eleger a monarquia como o melhor regime: a liberdade não é prerrogativa exclusiva de um determinado modelo de constituição (visto que se aventa a hipótese de vigorar tanto num governo de soberania popular, numa oligarquia como numa monarquia), mas é critério decisivo na aferição da qualidade do mesmo; o respeito pelos nomoi pátrios traduz o que, numa linguagem moderna, poderíamos

${ }^{14}$ Veja-se o recurso abundante a vocabulário da raiz kak-. No seu estudo, Ferrill (1978, 391-97) documenta com exemplos vários o uso herodotiano do termo tyrannos aplicado aos reis orientais com esse sentido negativo.

${ }^{15} 3.80 .5$.

163.80 .3 .

173.82 .5 . 
designar de 'conservadorismo' ideológico. Ou seja, Dario, em última instância, confessa preferir a monarquia a qualquer outro sistema governativo (mesmo que esse se paute pela excelência ${ }^{18}$ ) por razões de conformidade à tradição persa. $\mathrm{E}$ esta, em termos políticos, era monárquica. A figura do governante único, evocada como abonação da escolha de Dario, não o esqueçamos, é precisamente Ciro, rei fundador do Império Persa, nascido da libertação do jugo da Média. Lendo nas entrelinhas do discurso do futuro rei persa, é, pois, a seguinte a lógica da sua argumentação: se os Persas têm vivido sob a intendência de um monarca, desde que se libertaram da sujeição opressiva dos Medos, não há qualquer argumento válido para contestar a sapiência de um 'costume' (nomos) pátrio e incorrer na sua perniciosa 'transgressão' (anomia).

As transgressões ao nomos, não restringidas, como aqui, ao plano meramente institucional, constituem, em grau diverso, um dos traços mais marcantes dos perfis dos monarcas persas, governantes insolentes, que, à luz da visão grega da condição humana, se encontram fatalmente condenados à ruína. No fim desventurado desses líderes de homens está simbolicamente contido o anúncio inevitável da queda do regime a que dão corpo, o império.

Quanto à virtude libertadora da monarquia, nos termos em que é evocada, só faz sentido para quem passa de um estado de submissão ao de domínio. É o que sucede precisamente no contexto histórico em que Heródoto situa o «Diálogo dos Persas», após a deposição do governo do Mago usurpador, Gaumata. Mas, se tivermos em conta a perspetiva dos Gregos, por ocasião das invasões dos reis persas, percebemos que é por idêntica razão que o historiador lhes coloca na boca queixas acesas contra a escravidão que para eles acarreta o governo (tirânico) de um só senhor, o monarca oriental, pois priva-os da liberdade. Em suma: monarquia tanto significa liberdade como escravidão, depende da perspetiva.

\section{MATERIALizaÇÕES DO REgime: OS RETRATOS DOS MONARCAS}

Desde a publicação, em 1966, da obra de referência Form and Thought in Herodotus de H. R. Immerwahr que se identificou um padrão narrativo comum ao retrato dos chefes dos povos bárbaros contemplados nas Histórias. Condicionados pelos princípios universais da instabilidade da fortuna e da fragilidade da condição humana, todos os líderes vivem um percurso de ascensão e queda (que pode ser apenas de declínio ou de total destruição). O que me proponho fazer não é acompanhar pari passu essa biografia dramatizada dos reis persas (análise que vários estudiosos consagrados já levaram a cabo ${ }^{19}$ ). Não é minha intenção, igualmente, dar conta da presença, nos retratos dos governantes únicos (mounarchoi),

\footnotetext{
${ }^{18}$ Cf. 3.82.2.

${ }^{19}$ Veja-se Waters 1971, Gammie 1986, Silva 1995, 1997 e 2000.
} 
de todos os marcadores das identidades tirânica e monárquica apresentados no célebre passo de teorização política, por mim brevemente analisado na primeira parte desta intervenção ${ }^{20}$. Pretendo, sim, demonstrar em que medida o historiador exemplifica, na caracterização e atuação das suas personagens, sobretudo aqueles fundamentos políticos que, à luz da mentalidade do autor e dos seus mais diretos destinatários, os Gregos, são fundamentais ao exercício do poder: a lei e a liberdade.

No que concerne a importância conferida ao nomos, é por demais conhecido o primado que Heródoto lhe reconhece em todas as culturas ${ }^{21}$. Como o que nos interessa agora considerar é a relação do governante com a lei, é sobre a imagem do rei-juiz que me irei debruçar. Se, como vimos no «Diálogo dos Persas», o monarca elogiado por Dario é um indivíduo da melhor índole (aristos) e observar os costumes pátrios uma evidência de tal distinção, é natural que, quando os Medos escolheram o seu primeiro rei, tenham tido por critério de mérito ser ele o único homem a aplicar a justiça com retidão $0^{22}$. Embora os caps. 96-101 do livro I se reportem a um monarca medo (e não a um persa), Déjoces, o primeiro rei dos Medos, não podemos esquecer que os dois povos (e respetivas ideologias régias) se fundem, graças aos laços de sangue que ligam Ciro, também ele o primeiro rei (agora) dos medo-persas, ao avô, o último soberano da Média independente e dominadora, Astíages. Ou seja, conhecer a imagem que Heródoto desenha do nascimento da monarquia meda é, necessariamente, aceder aos fundamentos da monarquia persa (ou talvez fosse melhor chamar-lhe monarquia medo-persa) ${ }^{23}$.

No episódio em apreço, dois termos são usados para designar o exercício do

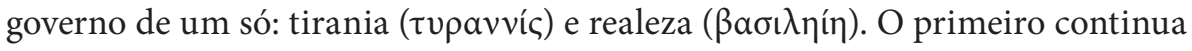
a ter uma conotação negativa, designando um poder despótico, ao passo que o segundo é sinónimo de soberania legítima ${ }^{24}$. Esta diferença semântica decorre dos contextos em que são empregues. A palavra «tirania» aparece duas vezes. Embora a primeira ocorrência, se tomada isoladamente, possa corresponder ao valor neutro de 'soberania', o facto de ser esse o termo usado para designar o verdadeiro, mas inconfesso, móbil da atuação jurídica exemplar de Déjoces consiste num aviso ao leitor da natureza despótica das suas intenções. Estas serão desveladas por completo, assim que lhe for confiada a 'realeza'. Note-se, ainda,

${ }^{20}$ Sobre este assunto, veja-se: Romilly 1959, Evans 1981, Rocha Pereira 1981 e 1990, Lateiner 1984, Pelling 2002.

${ }^{21}$ Ideia sintetizada de forma magistral na máxima atribuída, por Heródoto (3.38.4), a Píndaro, segundo a qual a lei é rainha de todas as coisas (fr. 169 a, Snell-Maehler). Sobre os valores de nomos e sua importância na obra herodotiana, leia-se: Evans 1965, Humphreys 1987. Quanto aos significados do termo e evolução do conceito na Grécia antiga, veja-se Ostwald (1969, 1-54) e Romilly (1971, 51-71).

${ }^{22} 1.96 .3$.

${ }^{23}$ Dewald $(2002,27)$ reconhece que este episódio permite, implicitamente, uma crítica e análise do desenvolvimento do poder monárquico.

${ }^{24}$ Concordo, pois, com posição idêntica, defendida por Ferrill (1978, 388-91). 
que é a palavra basileus ${ }^{25}$ aquela que o historiador usa para designar o tipo de governante que os Medos pretendiam e que, quando surge, pela segunda vez, o termo tupavvís, este vem associado a um adjetivo com sentido pejorativo: $\chi \propto \chi \lambda \varepsilon \pi$ óc ('implacável, intransigente'). A inflexibilidade, mesmo aplicada ao exercício da justiça, como é o caso presente ${ }^{26}$, é reveladora, quanto a mim, de falta de moderação, virtude tão apregoada pelos Gregos e reverso do defeito mais censurado, aos homens em geral e ao tirano em particular, a hybris ${ }^{27}$. Atentemos na sequência segundo a qual no texto se alude aos dois regimes políticos.

Heródoto conta que a motivação para Déjoces se ter empenhado mais na aplicação da justiça no seio da sua aldeia foi por desejar ardentemente a tirania ( pulta para as funções políticas ${ }^{29}$. Além desta relação umbilical entre os poderes jurídico e político ${ }^{30}$, há que considerar, tal como vimos a propósito da fala de Dario no «Diálogo dos Persas», a faceta regeneradora da monarquia/realeza. Na

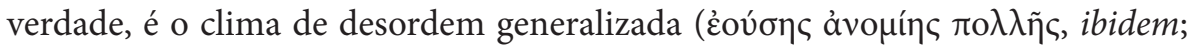

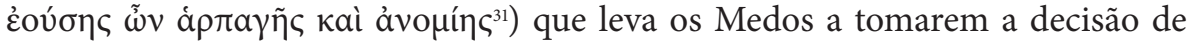
nomear um rei $(\beta a \sigma \iota \lambda \varepsilon ́ \alpha)$, cuja missão será precisamente estabelecer a boa ordem

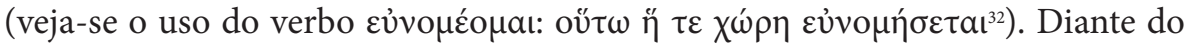
curriculum exemplar de Déjoces enquanto juiz, os Medos foram unânimes em elegê-lo rei ${ }^{33}$. Na mente dos Medos está, sem margem para dúvidas, o desígnio de serem governados por um basileus e não um tyrannos ${ }^{34}$. Mas será precisamente

${ }^{25} 1.98 .1$.

${ }^{26} 1.100 .1$

${ }^{27}$ Num estudo sobre a caracterização dos reis, Katherine Clarke (2015) explora até que ponto a manipulação do mundo natural pelos reis pode ou não ser lida como sinal do despotismo dos governantes. O seu estudo é particularmente interessante por chamar a atenção para a necessidade de considerarmos a origem do foco de censura, o que leva à conclusão de que muitas das vezes não se pode conceber essa visão negativa como sendo a posição do historiador, mas de terceiros.

${ }^{28} 1.96 .2$.

${ }^{29} \mathrm{Ou}$, como propõe Baragwanath $(2015,30)$, a atuação de Déjoces como juiz não reflete o seu caráter justo, mas sim o desejo de ser tirano da Média.

${ }^{30}$ Esta constitui, aliás, uma ideia comum à ideologia monárquica grega da época. Veja-se, a título ilustrativo, alguns exemplos relativos à Época Arcaica (Odisseia 19.9-11, em que se afirma que o rei irrepreensível decide de forma justa, ou seja, cabe-lhe exercer a justiça; Hesíodo, Trabalhos e Dias 35-39, passo em que se atribui aos basileis essa mesma função, que, no caso vertente, aplicam injustamente, por se deixarem corromper) e na Época Clássica (com destaque para a ênfase que Platão atribui ao «Justo» - to dikaion - como predicado distintivo da índole do «político verdadeiro», cf. e.g. O Político 293d8).

${ }^{31} 1.97 .2$.

32 1.97.3.

${ }^{33} 1.98 .1$.

${ }^{34}$ No seu estudo sobre o uso do termo tyrannos (em vez de basileus) para Édipo, em alguns passos na peça homónima de Sófocles, Knox (1954, 97-98) sublinha, tal como aqui, a ideia de que aquele designa o governante nomeado, mas não o descendente de uma linha hereditária monárquica. 
com a mudança de estatuto de homem privado para homem público, que se tornam claros os marcadores da identidade política tirânica de Déjoces.

Se o palácio ( $\left.\beta a \sigma \iota \lambda \eta^{\prime \prime} \alpha^{35}\right)$, uma exigência do novo senhor, pode ser entendido como um atributo material natural do poder régio (um verdadeiro signum imperii $\left.i^{36}\right)$, já a extrema fortificação de que é alvo o edifício e os procedimentos protocolares para o acesso dos súbditos ao rei parecem-me marcas camufladas de uma conceção tirânica do poder. Embora a inacessibilidade do rei possa ser vista sob o prisma favorável do reconhecimento que

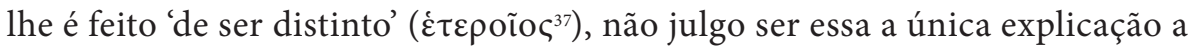
ter em conta. Aliás, Heródoto apresenta razões humanas bem diversas dessa para as seguintes medidas: a formação de uma guarda pessoal do rei, a inclusão da sua residência e tesouros no meio de uma cintura de sete muralhas, a obrigatoriedade de contacto indireto entre monarca e súbditos (através de mensageiros) e a criação de um corpo de espiões pessoais (os chamados «olhos e ouvidos do rei») ${ }^{38}$.

Foi para se proteger a si e aos seus tesouros que Déjoces mandou construir essa Ecbátana inexpugnável ${ }^{39}$. A desconfiança típica da alma tirânica, insegura dos seus méritos, revela-se na forma como afasta de si os seus pares, aqueles que,

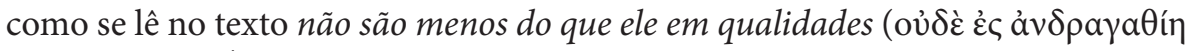

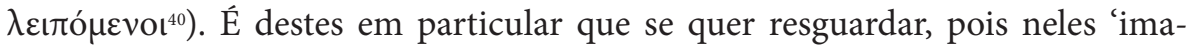

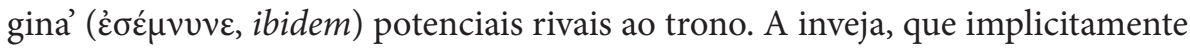
atribui aos outros, mais não é do que o reflexo de um vício pessoal, típico do tirano. Também a rede de espiões encobre e legitima defeitos próprios de uma governação opressora: a denúncia e a calúnia. Até a faceta de juiz, determinante como vimos para a nomeação de Déjoces como rei da Média, se mostra alterada pelo exercício despótico do poder. Os termos distintos em que o historiador apresenta Déjoces-juiz, antes e depois de ser investido das funções de chefe do povo, são suficientemente explícitos, pelo que passo a confrontar em citação os dois passos do texto:

Pela sua forma de atuar, recebia dos concidadãos elogios de não pouca monta, de modo que as gentes das outras aldeias tomaram conhecimento de que

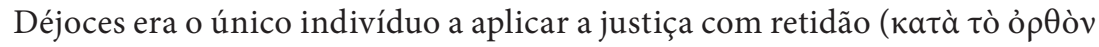

${ }^{35} 1.98 .4$.

${ }^{36}$ Outros são: trono, carro real, cavalos. Sobre as representações e as ideologias monárquicas dos Aqueménidas, veja-se Briant (1996, 217-65).

${ }^{37} 1.99 .2$.

${ }^{38}$ Dewald $(2002,28)$ qualifica este exercício da tirania de «autocracia burocrática», uma vez que complexifica o protocolo institucional e distancia, em muito, o governante dos governados.

${ }^{39} 1.99 .1$.

40 1.99.2. 
$\delta$ เสá $(\omega v)^{41}$.

Depois de tomadas estas medidas protocolares e de ter fortalecido o seu poder

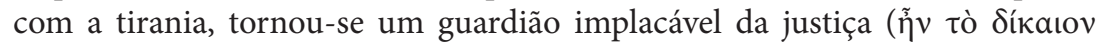
$\varphi v \lambda \alpha ́ \sigma \sigma \omega v \chi \alpha \lambda \varepsilon \pi \hat{o} \varsigma)^{42}$.

A tónica deixa de assentar numa ideia positiva de exercício imparcial da justiça para passar a distinguir-se pela intransigência. A situação é tanto mais grave para as partes do processo, quando, ao contrário do que sucedia quando Déjoces não governava, deixou de haver um contacto direto entre juiz e julgado(s). Ou seja, o exercício da lei faz-se em diferido, o que poderia comprometer a desejável retidão dos julgamentos. Não obstante esse distanciamento entre justiça e indivíduos, forçado pela ideologia política monárquica, a missão do juiz é resumida nestes termos: julgar cada crime de acordo com o mérito ${ }^{43}$.

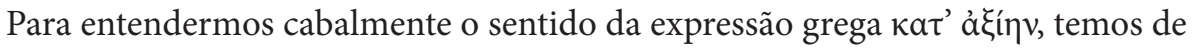
trazer à colação deste passo o cap. $137(\$ 1)$.

Aí Heródoto elogia o costume persa de fazer depender a aplicação de penas extremas de uma avaliação da conduta do réu na sua globalidade. Em causa está a interdição de, por causa de uma única falta, o rei-juiz condenar à morte e de os Persas aplicarem aos servos da sua casa um sofrimento irremediável. Tais

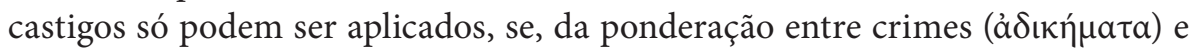

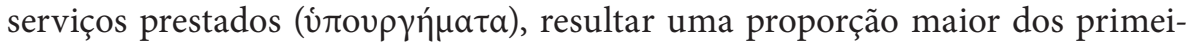
ros. Respeitam os monarcas persas este nomos, dando assim mostras de possuir a idoneidade que os torna merecedores do título de rei? Ou, pelo contrário, desrespeitam-no, incorrendo na transgressão (anomia) própria do soberano insolente (hybristes), o tyrannos? A resposta a estas interrogações encontramo-la nos retratos de Cambises e Dario. Se quanto ao primeiro não temos a mínima dúvida em identificá-lo com o exemplo mais bem acabado da galeria herodotiana de monarcas anomoi, o rei regenerador da monarquia persa é alvo de um tratamento mais complexo no que se refere à sua faceta de juiz. É por essa razão que dedicarei mais atenção ao perfil de Dario.

Padecendo de um estado de demência que lhe inspira uma espécie de «esquizofrénica» mania da perseguição, Cambises enceta uma série de execuções sumárias ${ }^{44}$. Por baixo da capa da inveja e da necessidade de desagravar pretensas injúrias à sua autoridade, o soberano esconde um carácter inseguro. É, por conseguinte, um indivíduo intolerante face a qualquer tipo de concorrência ao seu poder. A imaginária pretensão do irmão Esmérdis ao

\footnotetext{
${ }^{41} 1.96 .3$.

${ }^{42} 1.100 .1$.

${ }^{43} 1.100 .2$.

${ }^{44}$ Sobre o assunto veja-se Silva 1997, Soares (2003, 418-42).
} 
trono leva-o a cometer o primeiro fratricídio ${ }^{45}$. Segue-se-lhe a morte da irmãesposa, voz que decide silenciar, por intolerância absoluta face a manifestações de bom senso $^{46}$. O lastro homicida estende-se ainda a indivíduos fora do círculo familiar mais próximo, àqueles que, por serem seus pares (ò $\mu$ oíov $\varsigma^{47}$ ), facilmente rotularia de usurpadores. As censuras que estas e outras condenações à morte

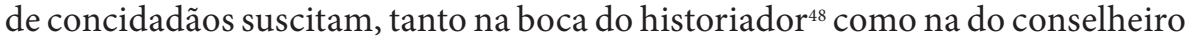
real, Creso ${ }^{49}$, ganham maior verosimilhança narrativa, se as entendermos precisamente como materializações do desrespeito (anomia) de Cambises pelo atrás elogiado costume pátrio da pena capital. Ao mandar matar pessoas sem

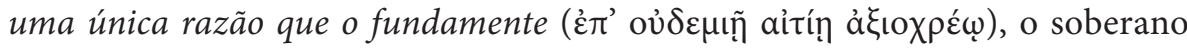
contradiz o código ético-jurídico persa, ou seja, não corresponde ao perfil do mounarchos ou basileus dikaios, mas ao do tyrannos hybristes, o mesmo é dizer adikos. Em resumo: insolente, injusto e transgressor são os qualificativos que ressaltam do retrato de Cambises e que legitimam a sua inclusão entre a galeria dos governantes tiranos ${ }^{50}$.

Passemos, agora, a considerar a imagem de Dario à luz do desempenho das competências de rei-juiz. Logo no início do seu reinado, o novo senhor do império persa delibera a condenação à morte de compatriotas do mais alto estatuto social: Intafernes, um seu par (pois fazia parte, como ele, do grupo dos sete conjurados responsáveis pela deposição do Mago usurpador, 3.118-119); Oretes, governador de Sardes ${ }^{51}$. Embora sequenciais no contexto da narração, os dois episódios revelam formas distintas de o rei aplicar a

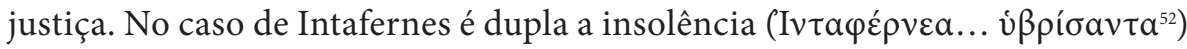
cometida. Não só desrespeitou o nomos recém-criado da prerrogativa concedida aos seis conjurados de poderem falar diretamente com o rei (exceto se ele estivesse deitado com uma mulher), como infligiu danos físicos irreparáveis

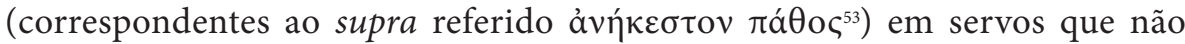
eram seus. A mutilação do nariz e das orelhas dos mensageiros, figuras indispensáveis desde os tempos do medo Déjoces ao protocolo régio, revela tanto a prepotência do nobre persa como o seu temor de um potencial rival ao trono. A solução que Dario toma para erradicar semelhante ameaça é, se quisermos usar o vocabulário jurídico que já nos surgiu anteriormente, 'implacável'. De

\footnotetext{
453.30 .

${ }^{46} 3.31-32$.

47 3.35.5.

${ }^{48}$ Ibidem.

${ }^{49} 3.36 .1$.

${ }^{50} \mathrm{O}$ seu sósia grego é Periandro de Corinto, figura que já tive ocasião de tratar noutra ocasião (Soares 2003, 442-48).

51 3.127-128.

${ }^{52} 3.118 .1$.

${ }^{53} 1.137 .1$.
} 
facto, a sentença de morte recai não só sobre o infrator, mas atinge também todos os varões da família (medida que visava eliminar potenciais vingadores da morte do chefe do clã).

No entanto, ao invés do seu antecessor, Dario não vem desenhado com as tintas carregadas da obstinação doentia. O restaurador da boa ordem na Pérsia goza de um carácter suficientemente ponderado para, sem comprometer a afirmação inequívoca da sua autoridade, reduzir uma pena que, pela sua radicalidade, poderia contribuir para criar dele a imagem do tirano e não a do monarca. De facto, aquele a quem Heródoto atribui o papel de defensor da monarquia como o melhor regime sabe fazer a leitura política correta do desgosto que tão implacável pena causaria na esposa de Intafernes. Concede-lhe, pois, a graça de poupar a vida do seu irmão e do filho primogénito. A misericórdia do monarca constitui, quanto a mim, uma estratégia narrativa para revelar como, no retrato do bom monarca-juiz, se fundem rigor e tolerância.

No episódio seguinte, a história da morte de Oretes, o leitor das Histórias depara com a exemplificação do nomos jurídico persa da condenação à morte mediante a avaliação ponderada da conduta do julgado. O poderoso governador da Lídia, Frígia e Iónia vem apresentado como autor de um vasto conjunto de crimes ( crescente de poder levou-o a liquidar dois ilustres aristocratas persas, Mitrobates e o filho Cranaspes, mortes que lhe valeram a passagem da província da Frígia para o seu controle. No entanto, como seria de prever, esse reforço de influência pessoal de um sátrapa não é visto com bons olhos pelo monarca recém-chegado ao poder, Dario, a braços, numa fase de afirmação de autoridade, com uma série de sublevações um pouco por todo o império ${ }^{56}$. Ou seja, a atuação de Oretes só pode ser vista pelo rei como um prejuízo (кakà $\delta \dot{\varepsilon} \mu \varepsilon \gamma a ́ \lambda \alpha^{57}$ ) e não um serviço

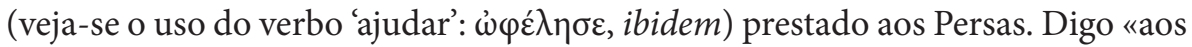

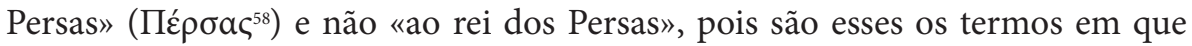
Dario expõe a culpa de Oretes perante uma assembleia dos mais notáveis Persas

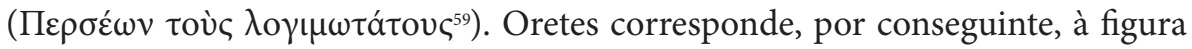
do inimigo público a abater. Reproduzo, de seguida, a argumentação empregue para encontrar um carrasco voluntário para a insolência intolerável (üßpıv oủ

${ }^{54} 1.126 .2$.

${ }^{55} 3.127 .1$.

${ }^{56}$ Essas revoltas vêm atestadas na inscrição de Behistun para as regiões de Elam, Babilónia, Assíria, Egito e Pártia, entre outras. Como refere Briant (1996, 127-28), não se pode falar com base no testemunho de Heródoto de uma verdadeira revolta da Lídia, mas apenas de insubordinação do seu sátrapa.

${ }^{57}$ 3.127.3.

${ }^{58} 3.127 .3$.

59 3.127.2. 


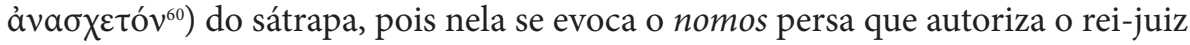
a condenar um súbdito à morte.

Entre vós há alguém que seja capaz de me trazer Oretes vivo ou de matá-lo? A esse homem que não prestou nenhum auxílio aos Persas, mas que, pelo contrário, lhes causou grandes males? ${ }^{61}$

Se, como tentámos demonstrar, Dario encarna as qualidades do rei-juiz e Cambises representa o seu reverso, no que se refere à faceta de rei libertador ela continua a estar retratada no primeiro, graças à sua condição de monarca regenerador do império, mas já surgira antes nas Histórias, ligada à caracterização de Ciro, o Grande Rei ${ }^{62}$.

De Dario já considerámos esta imagem de paladino da liberdade, a propósito do seu papel na recuperação do poder dos Persas face aos Medos. Nesse sentido podemos designá-lo de segundo unificador do império medo-persa, sob comando persa. O primeiro, o fundador do império e, como tal, justo merecedor do título de 'pai' ( $\left.\pi \alpha \tau \eta ́ \rho^{63}\right)$, Ciro, conquistou o apoio dos seus compatriotas na rebelião contra o jugo de Astíages com a promessa de os tornar livres ( $\gamma^{\prime} v \varepsilon \sigma \theta \varepsilon$ $\dot{\varepsilon} \lambda \varepsilon v ́\left(\theta \varepsilon o^{64}\right)$. Importa, todavia, não esquecer o real sentido que, no contexto da política expansionista intrínseca à ideologia monárquica oriental, assume a noção de liberdade. 'Ser livre' significa 'ser senhor de escravos'. Dos numerosos exemplos que, ao longo da obra, dão conta desse entendimento lembro apenas um outro, envolvendo também os Medos, aí apresentados na perspetiva oposta às que evoquei. Sobre eles conta Heródoto que, combatendo contra os Assírios em prol da liberdade, revelaram-se valerosos guerreiros e, ao repelirem a escravidão, tornaram-se livres ${ }^{65}$.

Mas será essa liberdade, à luz do pensamento grego, a verdadeira liberdade? A resposta a esta questão levar-nos-ia pelo caminho fascinante, mas longo e, por essa razão, de momento inviável, da visão herodotiana sobre a eleutheria grega. Lembro, apenas, que a sobejamente conhecida aversão dos Gregos (Atenienses e Espartanos, em especial) à soberania persa passa por uma mundividência diferente de soberania de um só e sua relação com a liberdade. A conhecida conversa entre Xerxes e Demarato, rei espartano exilado na sua corte, travada na sequência da inspeção das forças navais pelo monarca persa, encerra as ideias principais do pensamento grego nessa matéria. Na boca do Persa coloca

\footnotetext{
60 3.127.3.

${ }^{61}$ 3.127.3.

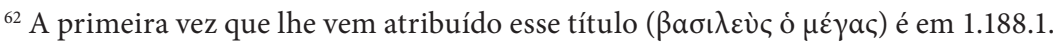

${ }^{63} 3.89 .3$.

${ }^{64}$ 1.126.6.

${ }^{65} 1.95 .2$.
} 
Heródoto um novo sentido de liberdade: não ser governado por um só homem. Eis os termos em que se exprime:

Se [os Lacedemónios] fossem governados à nossa maneira, por uma só pessoa, com receio dela, não só se tornariam melhores do que são por natureza, como poderiam, estando em desvantagem, fustigados pelo chicote, avançar contra um maior número [de adversários]. Todavia, entregues à liberdade, nenhuma dessas coisas serão capazes de realizar. ${ }^{66}$

A imagem opressiva que transparece deste retrato do soberano único fá-la o historiador ser verbalizada primeiro por um monarca persa, depois por um ex-diarca grego. Quanto a mim estamos, uma vez mais, perante a conhecida universalidade de valores, típica do texto herodotiano. Há, no entanto, diferenças de perspetiva, denunciadoras de identidades distintas. De facto, nas palavras pronunciadas por Demarato fica também implícita a ideia de que a liberdade dos Gregos decorre de não serem governados por um monarca. O estatuto de soberania não o reconhecem a um homem, mas sim a princípios normativos

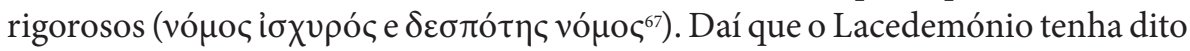

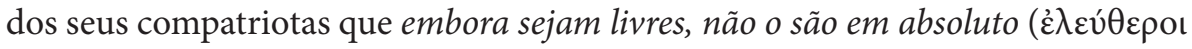

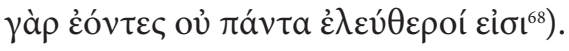

Em conclusão: a imagem herodotiana do papel da liberdade e da lei na construção da ideologia do governo de um só e respetivo governante assenta em princípios filosófico-políticos próprios da mundividência helénica do seu autor. Assim, a monarquia (ou realeza) corresponde à versão perfeita do regime, a tirania à forma degenerada; o monarca (ou rei) encarna virtudes, o tirano vícios.

Da conjugação entre esta bipolaridade política e a crença profundamente grega na fragilidade de todos os mortais sem exceção (onde se inclui, por conseguinte, o rei) resulta que nenhum dos retratos considerados corresponde ao modelo do governante de excelência. Se, nos casos de Ciro e Dario, ainda somos confrontados com o que proponho designar de «retratos mistos» (de monarca e tirano) - pois os comportamentos louváveis permitem compensar outros indignos - no de Cambises deparamos com um «retrato puro» (de tirano).

\footnotetext{
${ }^{66} 7.103 .4$.

${ }^{67}$ Cf. respetivamente 7.102 .1 e 7.704 .4 .

${ }^{68} 7.104 .4$.
} 


\section{Bibliografia}

Baragwanath, E. 2015. "Characterization in Herodotus." In Fame and Infamy. Essays for Christopher Pelling on Characterization in Greek and Roman Biography and Historiography, eds. R. Ash, J. Mossman and F. B. Titchener, 15-35. Oxford: Oxford University Press.

Briant, P. 1996. Histoire de l'empire perse. De Cyrus à Alexandre. Paris: Fayard.

Cartledge, P. 2009. Ancient Greek Political Thought in Practice. Cambridge: University Press.

Clarke, K. 2015. "Putting up Pyramids, Characterizing Kings." In Fame and Infamy. Essays for Christopher Pelling on Characterization in Greek and Roman Biography and Historiography, eds. R. Ash, J. Mossman and F. B. Titchener, 37-51. Oxford: Oxford University Press.

Dewald, C. 2003. "Form and Content: the Question of Tyranny in Herodotus." In Popular Tyranny: Sovereignty and Discontents in Classical Athens, ed. K. Morgan, 25-38. Austin: University of Texas Press.

Evans, J. A. S. 1965. “Despotes nomos.” Athenaeum 43:142-53.

Ferrill, A. 1978. "Herodotus on tyranny." Historia 27 (3):385-98.

Gammie, J. G. 1986. "Herodotus on kings and tyrants: objective historiography or conventional portraiture?" Journal of Near Eastern Studies 45 (3):171195.

Humphreys, S. C. 1987. "Law, Custom and Culture in Herodotus." Arethusa 20:211-20.

Immerwahr, H. R. 1966. Form and Thought in Herodotus. Cleveland: Scholars PR.

Knox, B. 1954. "Why is Oedipus Called Tyrannos?" CJ 50 (3):97-102, $130=1979$. "Why is Oedipus Called Tyrannos?" In Word and Action. Essays on the Ancient Theater, 87-95. Baltimore / London: The John Hopkins University Press.

Lasserre, F. 1976. "Hérodote et Protagoras: le débat sur les constitutions.” $M H$ 33 (2):65-84.

Lateiner, D. 1984. "Herodotean historiographical patterning: the constitutional debate." Quaderni di Storia 20:257-84.

Evans, J. A. S. 1981. "Notes on the debate of the Persian Grandees in Herodotus 3, 80-82." Quaderni Urbinati di Cultura Classica 36:79-84.

Ostwald, M. 1969. Nomos and the Beginnings of the Athenian Democracy. Oxford: Oxford University Press.

Parker, V. 1988. “Túpavvoc.The semantics of a political concept from Archilochus to Aristotle." Hermes 126 (2):145-72. 
Pelling, C. 2002, "Speech and action: Herodotus' Debate on the Constitutions." Proceedings of the Cambridge Philosophical Society. Vol 48, 123-58. Cambridge: Cambridge University Press.

Rocha Pereira, M. H. 1990. “O 'Diálogo dos Persas' em Heródoto." In Estudos Portugueses. Homenagem a António José Saraiva, 351-62. Lisboa: Ministério da Educação / Instituto de Cultura e Língua Portuguesa / Faculdade de Letras da Universidade de Lisboa.

_. 1981. "O mais antigo texto europeu de teoria política." Nova Renascença 1:364-70.

Romilly, J. 1971. La loi dans la pensée greque des origines à Aristote. Paris: Société d’Édition "Les Belles Lettres".

—. 1959. "Le classement des constitutions d'Hérodote à Aristote." Revue des Études Greques 72:81-99.

Rosivach, V. J. 1988. “The Tyrant in Athenian Democracy.” QUCC 59:43-57.

Silva, M. F. 2000. "O desafio das diferenças étnicas em Heródoto. Uma questão de inteligência e saber." Humanitas 52:3-26.

_ 1997. "Cambises no Egipto. Crónica de um rei louco." In Historiografía y bibliografia, Actas del coloquio internacional sobre historiografia y biografia (de la antiguedad al renac.), eds. J. A. Sanchez Marín, J. Lens Tuero e C. L. Rodríguez, 1-14. Madrid: Ediciones Clasicas.

_. 1995. "Dario, o Grande Rei, personagem em Histórias de Heródoto." Máthesis 4:63-88.

Soares, C. 2016. "Regimes políticos nas Histórias de Heródoto. O "Diálogo dos Persas" (3. 80-82)." In Pólis/Cosmópolis: Identidades Globais \& Locais, coords. Carmen Soares, Maria do Céu Fialho e Thomas Figueira, 43-52. Coimbra / São Paulo: Faculdade de Letras da Universidade de Coimbra.

_. 2014a. "Theoria e práxis política em Heródoto." Cuadernos de Filología Clássica: Estudios griegos e indoeuropeus 24:57-79.

— 2014b. "Diálogos nas Histórias de Heródoto entre teoria e praxis política. Tirania e democracia: contrastes e semelhanças." Phoînix 20 (1):25-39.

-2003. A morte em Heródoto. Valores universais e particularismos étnicos. Lisboa: Fundação Calouste Gulbenkian e Fundação para a Ciência e Tecnologia.

Waters, K. H. 1971. Herodotus on Tyrants and Despots. A Study in Objectivity. Historia Einzelschriften 15. Wiesbaden: Franz Steiner-Werlag. 
